\title{
A Path Analysis of Factors Influencing the First Childbearing Decision-Making in Women in Shahroud in 2014
}

\author{
Nourossadat Kariman ${ }^{1}$, Maliheh Amerian ${ }^{2}$, Padideh Jannati ${ }^{3}$, Fatemeh Salmani ${ }^{4} \&$ Mazlumeh Hamzekhani ${ }^{2}$ \\ ${ }^{1}$ Reproductive Health, Department of Midwifery and Reproductive Health, School of Nursing and Midwifery, \\ Shahid Beheshti University of Medical Sciences, Tehran, Iran \\ ${ }^{2}$ Midwifery, Department of Midwifery, School of Nursing and Midwifery, Shahroud University of Medical \\ Sciences, Shahroud, Iran \\ ${ }^{3}$ Midwifery, Department of Midwifery and Fertility Health, School of Nursing and Midwifery, Shahid Beheshti \\ University of Medical Sciences, Tehran, Iran \\ ${ }^{4}$ Biostatistics, Department of Statistics, School of Paramedical Sciences, Shahid Beheshti University of Medical \\ Sciences, Tehran, Iran \\ Correspondence: Maliheh Amerian, Department of Midwifery, Shahroud University of Medical Sciences, \\ Shahroud, Iran. Tel: 98-23-3239-5054. E-mail: m.amerian43@yahoo.com
}

Received: December 2, 2015 Accepted: January 7, 2016 Online Published: February 24, 2016

doi:10.5539/gjhs.v8n10p24 URL: http://dx.doi.org/10.5539/gjhs.v8n10p24

\begin{abstract}
Background and Objectives: Normal fertility follows a set of biological, social and cultural rules and regulations; controlled fertility, however, follows the rules and regulations of the family. The present study was therefore conducted to identify the factors influencing the first childbearing decision-making in women living in Shahroud, Iran, in 2014.

Materials and Methods: The present descriptive cross-sectional study was conducted on 300 randomly-selected pregnant women admitted to health centers in Shahroud. The utilized data collection tools included a demographic and obstetrics questionnaire, a quality of life questionnaire, the ENRICH Marital Satisfaction Scale, the Snyder Hope Scale and the Multidimensional Scale of Perceived Social Support. Data were analyzed in SPSS-17 and the direct or inverse effects of the factors influencing the first childbearing decision-making were examined in AMOS-20.

Results: The results obtained revealed marital age to have the highest degree of correlation with the first childbearing decision-making in women $(\mathrm{r}=0.90$ and $\mathrm{P}<0.001)$. Once the statistically insignificant paths were eliminated, marital age was found to have the highest direct effect $(\beta=0.63)$ on the first childbearing decision-making, followed by other factors including economic status $(\beta=0.07)$, hopefulness $(\beta=-0.07)$ and quality of life $(\beta=-0.05)$. The inverse effects of marital age $(\beta=0.01)$, social support $(\beta=-0.01)$ and quality of life $(\beta=-0.01)$ on the first childbearing decision-making were found to be significant in women $(\mathrm{P}<0.001)$.
\end{abstract}

Conclusion: Many factors are involved in the process of childbearing decision-making, including individual factors (marital age, hopefulness and quality of life), familial factors (marital satisfaction) and social factors (social support). Healthcare institutions and policymakers should adopt strategies that can help couples bear their desired number of children within an appropriate time frame through ameliorating their social, economic and familial conditions.

Keywords: decision-making, childbearing, factors influencing the first childbearing decision-making

\section{Introduction}

One of the most significant demographic changes of the past 3 decades is the sharp decrease in fertility throughout the world, especially in developing countries. Despite the range of variation in fertility in developing countries, the number of developing countries with sub-replacement fertility is on the rise (Hosseini \& Shavazi, 2009). The drop in fertility and birth rate affects not only the population growth rate and subsequently the adjustment of the acceleration of the population growth, but also the composition and structure of the population and will gradually change the society's age structure from the dominance of younger ages to the dominance of 
older ages (Kalantari et al., 2010). In Iran, the period of fertility transition corresponds to economic, social and traditional changes in families, which have altered reproductive behaviors related to marriage and childbearing and fertility trends as a result. In line with these changes, the total fertility rate per woman dropped to 1.8 in 2009 from 7.7 in 1966 (Aghajanian \& Mehryar, 1999; Abbasi-Shavazi et al., 2009).

Based on a 2011 census, the country's fertility rate was reported as 1.7 (Keshavarz and Baghery Ghanbarabadi, 2012). Moreover, the World Bank has estimated Iran's population growth rate to have dropped to $1.95 \%$ in 2010-2014 and to further drop to $1.23 \%$ in $2015-2019$ and to $1.13 \%$ in 2020-2024 (Kalantari et al., 2010). Normal fertility follows a set of biological, social and cultural rules and regulations; controlled fertility, however, follows the rules and regulations of the family, which constitute the most influential factor in the mean birth rate of couples (Hosseinzadeh et al., 2010) .

Childbearing is an irreversible process that demands a permanent commitment for supporting and protecting a child for years to come. In most societies, what most concerns individuals and brings them doubt about childbearing is the actual fact of having a child and its timing. The separation of sexual relationships from childbearing has also resulted in a different lifestyle unprecedented in the history of humankind (Kariman et al., 2014b). Given the increased rate of pregnancies occurring both before and after women's actual fertility age and given the incident's numerous adverse complications and outcomes for the women themselves and their family and the society at large, researchers have warned about possible future changes in the onset of childbearing and about potential delays in the first childbearing against a backdrop of fertility decline and sub-replacement fertility (Razeghi et al., 2013). Researchers believe that the amount of time spent for childbearing decision-making is increasing (Beck \& Beck-Gernsheim, 2002). One of the main reasons for this increase is that, in line with reproductive freedom, children have become a valuable property. A long-term process of reflection and intellectual debate may therefore precede childbearing. Previous studies on fertility have failed to take into account the process of childbearing decision-making (Rijken \& Knijn, 2009; Kariman et al., 2014a).

Various studies have found that fertility rates depend on the economic, social and familial factors at play in the society; identifying these factors is therefore a necessary step in population control. Ascertaining significant relationships between fertility and any of these factors can help predict fertility rates based on the changes occurring in these factors and can then help positively alter their direct or inverse effects on fertility and accomplish a better population control (Akaberi et al., 2008). Many studies have examined the changes in fertility rates and in the factors influencing fertility in Iran and other countries (Testa et al., 2012; Kohan et al., 2012). The results of these studies show the direct relationship of fertility with women's age (Kariman et al., 2014b; Daniluk \& Koert, 2012; Brennan et al., 2011; Mills et al., 2011), marital age (Hosseinzadeh et al., 2010; Kariman et al., 2014b; Taghizadeh et al., 2015), sexual preferences (Akaberi et al., 2008; Mills et al., 2011; Bhat \& Zavier, 2003; Adibi Sedeh et al., 2012), desired number of children (Kariman et al., 2014a; Akaberi et al., 2008; Testa et al., 2012; Kohan et al., 2012; Daniluk \& Koert, 2012; Brennan et al., 2011; Mills et al., 2011; Bhat \& Zavier, 2003; Sedeh et al., 2012; Tavares, 2010) and child mortality (Sadeghi et al., 2010) and its indirect relationship with marital age (Sedeh et al., 2012) and couples' level of education (Tavares, 2010; Sadeghi et al., 2010).

Moreover, fertility rates may decrease due to various socio-economic conditions. Identifying the most crucial factors influencing childbearing can help design efficient interventions, facilitate policy maker's decision-making in the current legal system and help healthcare providers learn how to assist women in this important process and present useful strategies and interventions.

\section{Materials and Methods}

The present cross-sectional study was conducted on 300 eligible pregnant women admitted to healthcare centers and private clinics in Shahroud from March/April to August/September 2014. Participants were selected through multi-stage cluster sampling. The healthcare centers in Shahroud were first divided into a northern division and a southern division. Urban healthcare centers in each division were then determined as clusters. A number of healthcare centers were selected through simple random sampling during the first stage, and the sample size for each center was then determined based on the population covered by the center through quota sampling. Convenience sampling was then carried out in the healthcare centers. Through a review of literature and the examination of research variables and to allow 10-15 samples for each variable, the sample size required for the study was calculated as 300 and was then increased to 360 to account for a drop-out rate of $20 \%$ (Munro, 2005). The study inclusion criteria consisted of being Iranian, being married for the first time and being primiparous. The study exclusion criteria consisted of having an unwanted pregnancy, unplanned pregnancy, a history of abortion and a history of infertility. Data were collected using a demographic and obstetrics questionnaire 
(including items on participant's and husband's age, participant's and husband's education, participant's and husband's occupation, place of birth, place of residence, marital age, duration of marriage, desired pregnancy spacing and desired number of children), a quality of life questionnaire (derived from the WHO quality of life questionnaire), the ENRICH marital satisfaction scale, the Snyder hope scale and the multidimensional scale of perceived social support.

The validity of the World Health Organization Quality of Life (WHOQOL)-BREF was determined through examining its face and construct validities, and the reliability of the questionnaire was examined through test-retest and with a minimum Cronbach's alpha value of 0.55 and a maximum value of 0.84 (Usefy et al., 2010; Asoodeh et al., 2010; Nejat et al., 2006).

The validity of the ENRICH marital satisfaction scale was calculated as 0.86 through the examination of its content validity and its reliability was confirmed with a Cronbach's alpha value of 0.78 (Asoodeh et al., 2010; Fowers et al., 1989). The validity of the Snyder hope scale has also been reported as favorable and over 0.7 through the examination of its content validity (Grewal \& Porter, 2007). Snyder et al. (2000) determined the reliability of their scale through test-retest and calculated its Cronbach's alpha as 0.81; and Ghobari et al. (2007) then reported the Cronbach's alpha obtained for the questionnaire as 0.88 (Snyder, 2000; Bonab et al., 2007). The validity of the multidimensional scale of perceived social support has also been confirmed using principal component analysis (Zimet et al., 1988). Different studies have reported the reliability of the scale with Cronbach's alpha values between 0.86 and 0.9 for the sub-scales and a value of 0.86 for the entire scale (Bruwer et al., 2008; Salimi et al., 2009). The reliability of the scales used in the present study was determined through test-retest and through the examination of the scales' internal consistency. The correlation between the scores obtained for the quality of life questionnaire, the ENRICH marital satisfaction scale, the Snyder hope scale and the multidimensional scale of perceived social support was calculated as $0.76,0.89,0.85$ and 0.73 with Cronbach's alpha values of $0.84,0.76,0.78$ and 0.82 , in respective order. After determining the validity and reliability of the scales and obtaining the approval of the $162^{\text {th }}$ meeting of the Ethics Committee of Shahid Beheshti University of Medical Sciences and obtaining a written letter of introduction from the School of Nursing and Midwifery at Shahid Beheshti University of Medical Sciences and obtaining permission from Shahroud University of Medical Sciences, the researchers began sampling by visiting the urban healthcare centers and private clinics in Shahroud. With the selection of women who met the inclusion criteria of the study, the researcher briefed participants on the objectives of the study in person and ensured them of the confidentiality of all their information. Participants then completed the scales individually after submitting their consent forms. The data obtained from the scales were analyzed in SPSS-17 and AMOS-20. Descriptive statistics were used to present and describe the data, prepare the tables and calculate the percentage, mean and standard deviation of the scores; inferential statistics were used to analyze the data and find the correlations. Pearson's correlation coefficient was also used to examine the correlation between the variables, and regression models were used to examine the correlation between the independent and dependent variables studied. A path analysis was used for examining the direct or inverse effects of the variables on the first childbearing decision-making. The level of statistical significance for the scales was determined as 0.05 .

\section{Results}

The 300 study subjects examined had a mean age of $24.81 \pm 3.92$ years, a mean marital age of $21.64 \pm 3.93$ and a mean duration of marriage of $3.17 \pm 1.68$. A total of $87 \%$ of the women were born in cities and $92.3 \%$ lived in cities. The women's mean desired number of children was $2.32 \pm 0.77$. A total of $52.3 \%(n=157)$ of the women had university education. A total of $80 \%(n=240)$ of the women were housewives. A total of $43 \%$ of the women were tenants. The majority of participants $(47.7 \%)$ used condoms as their method of contraception before pregnancy. All the participants were primiparous. The majority of the families (38\%) had a monthly income of 7,000,000 to 10,000,000 Rial. Table 1 presents the mean and standard deviation (SD) and the minimum and maximum values obtained for the main variables examined.

Table 1. Distribution of the factors' scores

\begin{tabular}{llll}
\hline Variable & Mean \pm SD & Minimum & Maximum \\
\hline Timing motherhood & $24.81 \pm 3.92$ & 18.00 & 38.00 \\
Marital age & $21.64 \pm 3.93$ & 13.00 & 37.00 \\
Hopefulness & $20.93 \pm 6.34$ & 15.00 & 48.00 \\
\hline
\end{tabular}




\begin{tabular}{llll}
\hline Variable & Mean \pm SD & Minimum & Maximum \\
\hline Marital satisfaction & $122.45 \pm 16.08$ & 52.00 & 171.00 \\
Perceive social support & $59.35 \pm 13.64$ & 12.00 & 84.00 \\
Quality of life & $99.72 \pm 12.8$ & 38.00 & 130.00 \\
\hline
\end{tabular}

To carry out the path analysis, the correlation between the variables was first examined through bivariate analyses. According to the results, marital age $(\mathrm{r}=0.907)$, duration of marriage $(\mathrm{r}=0.204)$ and economic status $(\mathrm{r}=0.19)$ were significantly and directly correlated with the timing of the first childbearing decision-making $(\mathrm{P}<0.01)$. However, the other childbearing variable examined, including marital satisfaction $(\mathrm{r}=-0.719)$, social support $(\mathrm{r}=-0.746)$, hopefulness $(\mathrm{r}=-0.418)$, quality of life $(\mathrm{r}=-0.310)$, the desired number of children $(\mathrm{r}=-0.122)$ and pregnancy spacing $(\mathrm{r}=-0.165)$ were significantly but inversely correlated with the timing of the first childbearing decision-making $(\mathrm{P}<0.01)$. Table 2 presents part of the results.

Table 2. Correlations between the timing of the first childbearing decision-making and marital satisfaction, perceived social support, hopefulness, quality of life and economic status

\begin{tabular}{lllllll}
\hline Variable & $\begin{array}{l}\text { Timing } \\
\text { motherhood }\end{array}$ & $\begin{array}{l}\text { Marital } \\
\text { satisfaction }\end{array}$ & $\begin{array}{l}\text { Perceived } \\
\text { social support }\end{array}$ & Hopefulness & $\begin{array}{l}\text { quality } \\
\text { of life }\end{array}$ & $\begin{array}{l}\text { economic } \\
\text { status }\end{array}$ \\
\hline $\begin{array}{l}\text { Timing } \\
\text { motherhood }\end{array}$ & 1.000 & & & & & \\
$\begin{array}{l}\text { Marital } \\
\text { satisfaction }\end{array}$ & $-.719^{\mathrm{a}}$ & 1.000 & & & & \\
$\begin{array}{l}\text { Perceived social } \\
\text { support }\end{array}$ & $-.746^{\mathrm{a}}$ & $.563^{\mathrm{a}}$ & 1.000 & & & \\
$\begin{array}{l}\text { Hopefulness } \\
\text { Quality of life }\end{array}$ &.$- .418^{\mathrm{a}}$ & .285 & $.342^{\mathrm{a}}$ & 1.000 & & \\
$\begin{array}{l}\text { Economic } \\
\text { status }\end{array}$ & $-.310^{\mathrm{a}}$ & $.249^{\mathrm{a}}$ & $.245^{\mathrm{a}}$ & $.324^{\mathrm{a}}$ & 1.000 & \\
\hline
\end{tabular}

${ }^{\mathrm{a}}$ Correlation is significant at the 0.01 level.

First, the normal distribution of the variables (using the Kolmogorov-Smirnov test), their homoscedasticity and the linear correlation between them were examined for the pathway analysis. The correlation between the variables was measured using the method of bivariate analysis (Table 2). As shown in the table, the timing of the first childbearing decision-making was inversely and significantly correlated with hopefulness, marital satisfaction and perceived social support. Meanwhile, there was a direct significant correlation between marital age and socio-economic status. The life regard index was directly related with the timing of the first childbearing decision-making, but the correlation was not significant.

The structural equation modeling was used to examine the effect of the factors influencing the first childbearing decision-making. The fit of the model was assessed through a number of indices. Given that the root mean square error of approximation (RMSEA) was lower than 0.08 and the comparative fit index (CFI), the normed fit index (NFI), the goodness of fit index (GFI) and the adjusted goodness of fit index (AGFI) were higher than 0.90, the model had a good fit. The relative chi-square, i.e. the ratio of chi-square to degrees of freedom, was calculated as 1.037 in the present study and was then deemed acceptable, showing the good fit of the model as it was lower than 3. The schematic plot of the structural model was fitted. Table 1 presents the measured coefficients. The results obtained showed that marital age had the highest and quality of life the lowest path coefficients in the experimental model yielded for the path analysis of factors influencing the first childbearing decision-making in women. 
Table 3. Goodness of fit indices for the model ${ }^{\mathrm{b}}$

\begin{tabular}{llllllll}
\hline Model index & $\chi^{2}$ & df & RMSEA & GFI & NFI & CFI & AGFI \\
\hline & 5.187 & 5 & 0.011 & 0.995 & 0.995 & 1 & 0.972 \\
\hline
\end{tabular}

${ }^{\mathrm{b}}$ Abbreviations: Root Mean Squared Error of Approximation(RMSEA),Comparative Fit Index (CFI),Normed Fit Index (NFI),Goodness of Fit Index (GFI),Adjusted Goodness of Fit Index (AGFI), chi square $\left(\chi^{2}\right)$,Degrees of freedom (df).

According to the results shown in Table 4, of all the direct paths, marital age $(\beta=0.63)$ had the highest effect on the timing of the first childbearing decision-making. Hopefulness also influenced the timing of the first childbearing decision-making indirectly through the inverse effects of quality of life, social support and marital age. Marital satisfaction $(\beta=-0.20)$, social support $(\beta=-0.17)$, hopefulness $(\beta=-0.07)$ and quality of life $(\beta=-0.05)$ also had an inverse effect the first childbearing decision-making.

Table 4. Path coefficients for the prediction of variables influencing the timing of the first childbearing decision-making

\begin{tabular}{|c|c|c|c|c|c|}
\hline \multirow{2}{*}{ Predictor variables } & \multicolumn{3}{|l|}{ Effect } & \multirow{2}{*}{ Model coefficient } & \multirow{2}{*}{ p-value } \\
\hline & Direct & Indirect & Total & & \\
\hline Marital age & 0.63 & 0.01 & 0.64 & 0.627 & $0.000 *$ \\
\hline Marital satisfaction & -0.20 & - & -0.20 & -0.203 & $0.000 *$ \\
\hline Perceive social support & -0.17 & -0.01 & -0.18 & -0.174 & $0.000 *$ \\
\hline economic status & 0.07 & - & 0.07 & 0.069 & $0.000 *$ \\
\hline Hopefulness & -0.07 & - & -0.07 & -0.065 & $0.002 *$ \\
\hline quality of life & -0.05 & -0.01 & -0.06 & -0.049 & 0.015 \\
\hline
\end{tabular}

Significant at the 0.05 level.

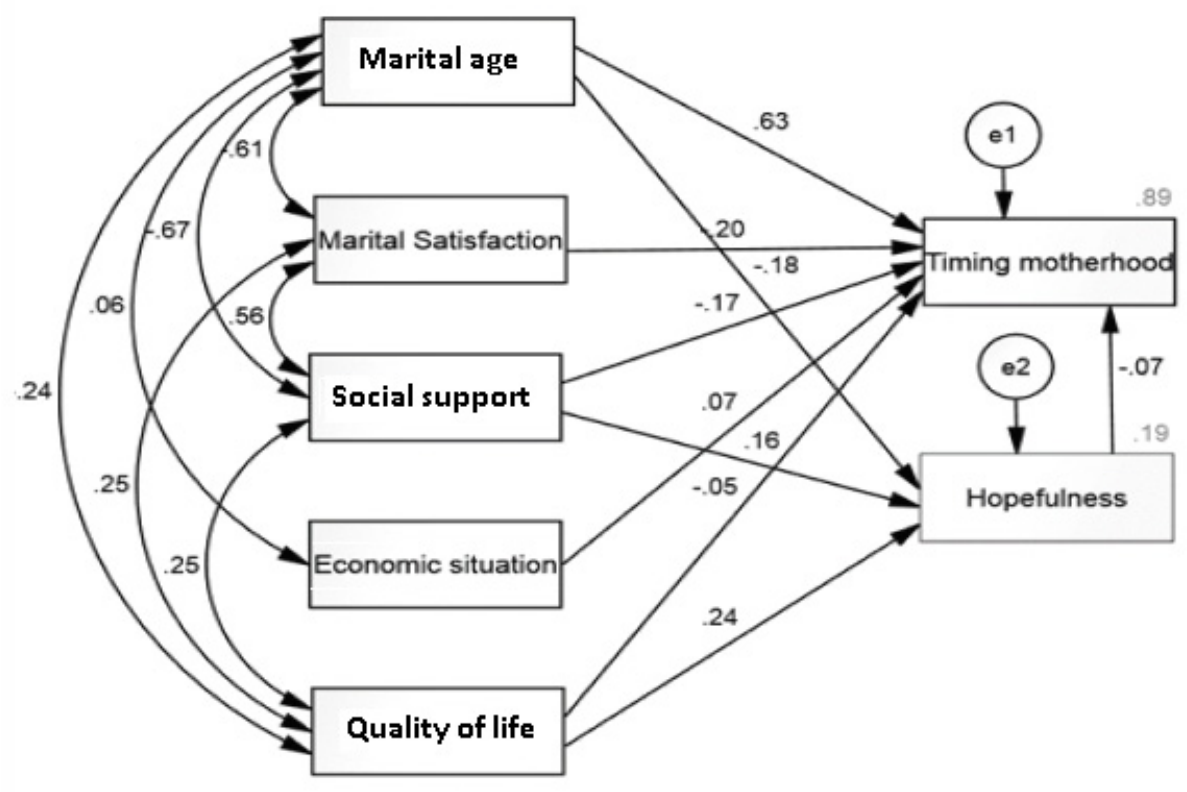

Figure 1. The results of the experimental model of the path analysis of the factors influencing the first childbearing decision-making

*Values on the path: The path coefficients or the beta weights (all the values obtained for the path coefficients are standard at $\mathrm{P}<0.05$ ) are significant.

*Values above the rectangles: The explained variance

*E1 and E2: Error variables 


\section{Discussion and Conclusion}

The results obtained show that socioeconomic changes and other changes in the family are associated with changes in values, motivations, attitudes and reproductive behaviors related to marriage, childbearing and fertility trends as a result. Theories aiming to increase fertility rates cannot be implemented without first preparing the socioeconomic and mental grounds required for the public to welcome these efforts.

The present study showed that women's level of education and economic status directly influence the timing of their first childbearing decision-making, with the former being the most effective factor involved in this decision-making. Women with higher levels of education have more information about contraceptive methods and their diversity. Researchers believe that between the socioeconomic status and the timing of the first childbearing decision-making in women; that is, the timing of the first childbearing decision-making increases with the family's income, level of education and access to facilities (Kariman et al., 2014b). In different studies the gap between marital age and the timing of the first childbearing decision-making to be highly influenced by the husband's occupational status reported (Razeghi et al., 2013; Akaberi et al., 2008). In their study on the effect of socioeconomic factors on female fertility rates, Hezarjaribi and Abbaspour (2010) showed that economic status has a negative effect on female fertility rates, as female fertility rates drop with an improved financial and economic status in the family (Hezarjaribi \& Abbaspour, 2010).

A study conducted by Ahmadian and Mehrabani (2012) revealed that women's level of education has such a great negative effect on their fertility rates that even exceeds the negative effect of men's level of education on women's fertility rates (Ahmadian \& Mehrbani, 2013). A study conducted by Kreyenfeld and Andersson (2014) on the data obtained from the German and Danish socio-economic panel showed that the rate of childbearing decreases significantly in individuals with high levels of education during periods of unemployment compared to in individuals with low levels of education (Kreyenfeld \& Andersson, 2014). In a study conducted by Bhrolcháin and Beaujouan (2012), an increased level of education in women and an increased rate of school enrollment in girls increased the age at first birth in developing countries (Ní.Bhrolcháin \& Beaujouan, 2012).

In the present study, marital age and the duration of marriage were significantly and directly correlated with the timing of the first childbearing decision-making, and participants who got married at younger ages had their first child earlier as well. Studies conducted proposed the increase in the age of marriage for women as a threat to their fertility and a factor involved in increasing the problems and diseases occurring during pregnancy and childbirth (Kariman et al., 2014a). Various studies have shown that the age at first marriage is a major intervening factor and the main determinant of the age at first birth that works alongside some of the other factors involved in the timing of the first birth and a significant increase in the risk of infertility, high-risk pregnancy, sexual problems and fatigue with the increase in women's age at first birth (Razeghi et al., 2013; Soleimani et al., 2005; Taghizadeh et al., 2015).

The results of a study conducted by Cooke et al. (2010) was inconsistent with the results of the present study (Cooke et al., 2010), as the majority of women in the study believed in having ample time for bearing children and did not believe in the adverse effects of giving birth at older ages. The disparity between the results of Cooke's study and the findings of the present study might be due to the higher trust the former's participants placed in the effectiveness of new methods of infertility treatment and their success rates, which had been communicated to them through the media and had consequently reduced their concerns about an increased age at first birth.

The present study also showed marital satisfaction to reduce the age at first birth. According to studies, there is a close relationship between couples' perceived marital quality and their childbearing motivations (Solchany, 2001). Some couples consider having children early in their marriage a threat to the chance of being alone with their spouse and enjoying their freedom, pursuing fun activities, traveling and spending time together, and thus delay their childbearing decision-making. Moreover, the uncertainty about fully knowing one's spouse (especially in the case of traditional marriages) and feelings of doubt about the stability of the marital relationship caused by disputes and consuming discussions over the course of getting to know one another lead to childbearing hesitations (Kariman et al., 2014b; Kariman et al., 2014a; Testa et al., 2012; Kariman et al., 2015; Klobas, 2011; Rijken, 2009; Samadaee-Gelehkolaee et al., 2014).

Some studies propose childbearing as an effective motivation for couples to resolves their marital problems through reducing their distrust and adding to their trust in one another (Testa et al., 2012; Friedman et al., 1994). The results of some empirical studies revealed the two effects that extremely favorable marital relationships had on childbearing, that is, a reinforced intention for childbearing and the decision in women to have fewer children (Kariman et al., 2014a, 2014b, 2015; Testa et al., 2012; Lainiala, 2011). 
Other factors that had a significant and inverse effect on the first childbearing decision-making in women included pregnancy spacing and the desired number of children. it seems that women from ethnic groups with different characteristics have rather similar fertility ideals that converged toward low fertility rates (Hezarjaribi \& Abbaspour, 2010). (Hosseini \& Shavazi, 2009). In a study conducted by Khadivzadeh et al. (2013), the desired number of children did not change significantly in the woman from when they got married to when they gave birth and couples preferred to have long intervals between their marriage and the birth of their first child (Khadivzadeh et al., 2013), which were consistent with the results of the present study. In a study conducted by Akaberi et al. (2008), the desire to have several children had resulted in higher fertility rates. The inconsistency between Akaberi's results and the findings of the present study may be due to cultural and environmental differences (Akaberi et al., 2008).

There was a significant inverse relationship between perceived social support and the timing of the first childbearing decision-making. The increasing number of articles published in different journals about social support, the positive effects of the availability of social support and the negative outcomes of its unavailability reveal the great role of social factors in childbearing (Kariman et al., 2014b; Khadivzadeh et al., 2013; Long \& Johnson, 2000; Keim et al., 2009).

Hopefulness was another variable that had a significant inverse effect on the timing of the first childbearing decision-making in women. More hopeful women were quicker to decide to have a child. Kariman et al. (2014) showed an inverse relationship between women's hopefulness and the timing of their first birth (Kariman et al., 2014b), which was consistent with the findings of the present study. Furthermore, a study aiming to examine the increase in fertility rates and the factors influencing fertility in women living in Andimeshk, Iran, showed a positive direct relationship between individuals' attitude toward fertility and fertility rates. Adair found women's interest in becoming a mother to be a strong predictor of the first childbearing decision-making. Some foreign studies found childbearing to be a motivation for the promotion of femininity and considered women's independence and family motivation a factor influencing their childbearing decision-making (Adair, 2013; Benzies et al., 2006; Söderberg et al., 2012). Quality of life was another factor influencing the first childbearing decision-making in women. Different studies have proposed perceived physical and mental readiness to accept the responsibility of motherhood and the lack of chronic diseases as the main reasons for making the decision to have children. Testa et al. (2011) found that women's level of satisfaction with their spouse's participation in household chores and child care had an insignificant effect on the probability of their decision to have children, which was inconsistent with the results of the present study, perhaps due to the different sociocultural contexts of the two societies studied (Testa et al., 2011).

Based on the results of the model extracted from Kariman's study (2014a), factors influencing the first childbearing decision-making are rooted in numerous other factors themselves. The life regard index was eliminated from the model proposed in Kariman's study due to its insignificance, and only hopefulness and marital satisfaction had an indirect relationship with the first childbearing decision-making in Iranian women. Meanwhile, the model extracted from the present study showed a significant relationship between quality of life and the timing of the first birth and also found that marital age, perceived social support and quality of life affected the timing of the first childbearing decision-making directly as well as indirectly through the effect of hopefulness (Kariman et al., 2014b).

The variables that entered the regression analysis as factors influencing the first childbearing decision-making explained an average of $80 \%$ of the variance in fertility. Although this coefficient of determination reveals a rather highly accurate selection of variables for entering the regression analysis, this finding is limited to Shahroud and does not provide definitive evidence for being generalized across Iran. Furthermore, the present study was cross-sectional in design and cannot be considered a validated examination of decision-making processes. Future studies are recommended to examine the effect of the government's new policies on childbearing decision-making.

\section{Final Conclusion}

The results of the present study revealed that marital age, marital satisfaction, social support, economic status, hopefulness and quality of life have a direct influence on the timing of the first birth, with marital age exerting the highest effect. Moreover, marital age, perceived social support and quality of life affect the timing of the first childbearing decision-making directly as well as indirectly through the effect of hopefulness. Policymakers should adopt strategies that help women bear their desired number of children within an appropriate time frame and that also facilitate the first childbirth decision-making in women choosing to pursue higher education and hold an employment. The reducing effects of a delay in the first birth can thus be controlled in future pregnancies 
and the continuous decrease in fertility can also be prevented.

\section{Acknowledgements}

The present study was part of a master's thesis in Midwifery at Shahid Beheshti University of Medical Sciences. The researchers would like to express their gratitude to the Research Committee of the School of Nursing and Midwifery and all the participants who cooperated in conducting this study.

\section{Conflict of Interest}

The authors declare that there is no conflict of interests regarding the publication of this paper.

\section{References}

Adair, L. E. (2013). Fertility decision making: To what extent do adaptations, social pressures, and individual differences influence plans to have a child? Kansas State University. Retrieved from http://hdl.handle.net/ $2097 / 15700$

Ahmadian, M., \& Mehrbani, V. (2013). Women's education and fertility in Tehran: An economic approach. Journal of Economic Research (Tahghighat-E-Eghtesadi), 48, 1-20. Retrieved from http://en.journals.sid.ir/ ViewPaper.aspx?ID=316521

Akaberi, A., Mahmoudi, M., Zeraati, H., \& Majlesi, F. (2008). Study of the relationship of socioeconomic and demographic factors with fertility. Journal of Sabzevar University of Medical Sciences, 15, 45-40. Retrieved from http://en.journals.sid.ir/ViewPaper.aspx?ID=171256

Asoodeh, M. H., Khalili, S., Daneshpour, M., \& Lavasani, M. G. (2010). Factors of successful marriage: Accounts from self described happy couples. Procedia-Social and Behavioral Sciences, 5, 2042-2046. http://dx.doi.org/10.1016/j.sbspro.2010.07.410

Beck, U., \& Beck-Gernsheim, E. (2002). Individualization: Institutionalized individualism and its social and political consequences. London, Sage. Record number: 1641703. ISBN: 0761961119.

Benzies, K., Tough, S., Tofflemire, K., Frick, C., Faber, A., \& Newburn-Cook, C. (2006). Factors influencing women' s decisions about timing of motherhood. Journal of Obstetric, Gynecologic, \& Neonatal Nursing, 35, 625-633. PMID: 16958718. http://dx.doi.org/10.1111/j.1552-6909.2006.00079.x

Bonab, B., Lavasani, M., \& Rahimi, H. (2007). Hope, purpose in life, and mental health in college students. International Journal of the Humanities, 5, 127-132. Retrieved from http://ijh.cgpublisher.com/product/ pub.26/prod.1088

Brennan, D., Pirritano, M. P., Tucker, L., \& Lampic, C. (2011). Fertility awareness and parenting attitudes among American male and female undergraduate university students. Human Reproduction, 27, 1375-1382. PMID: 22407698

Cooke, A., Mills, T., \& Lavender, T. (2010). 'Informed and uninformed decision making'-Women's reasoning, experiences and perceptions with regard to advanced maternal age and delayed childbearing: A meta-synthesis. International Journal of Nursing Studies, 47, 1317-1329. http://dx.doi.org/10.1016/j. ijnurstu.2010.06.001

Daniluk, J., \& Koert, E. (2012). Childless Canadian men's and women's childbearing intentions, attitudes towards and willingness to use assisted human reproduction. Human Reproduction, 27, 2405-2412. PMID: 22684907. http://dx.doi.org/10.1093/humrep/des190

Fowers, B. J., \& Dh, O. (1989). ENRICH Marital Inventory: A discriminant validity and cross-validation assessment. Journal of Marital and Family Therapy, 15, 65-79. http://dx.doi.org/10.1111/j.1752-0606. 1989.tb00777.x

Grewal, P. K., \& Porter, J. E. (2007). Hope theory: A framework for understanding suicidal action. Death Studies, 31, 131-154. http://dx.doi.org/10.1080/07481180601100491

Hezarjaribi, J., \& Abbaspour, A. (2010). The effect of socio-economic factors on women's fertility. Social Research, 3, 140-153. Retrieved from http://philpapers.org/rec/HEZTEO

Hosseini, H., \& Shavazi, M. J. A. (2009). Ideational change and its impact on fertility behavior and attitudes of Kurd and Turk women. Women's Research Journal, 7, 55-84. Retrieved from http://en.journals.sid.ir/ ViewPaper.aspx?ID=150091

Hosseinzadeh, H., Nuhjah, S., \& Sharifi, M. (2010). Fertility pattern, marriage age and contraceptive methods usage between different ethnic groups in the city of Ahwaz in 1388. Jornal of Social Sciences 4, 67-97. 
Retrieved from http://en.journals.sid.ir/ViewPaper.aspx?ID=211991

Kalantari, S., Abbaszadeh, M., Mozaffari, F. A., \& Rakaei, M. A. M. (2010). The sociological study of attitude to child bearing and it's some related. Journal of Applied Sociology, 21, 83-104. Retrieved from http://en.journals.sid.ir/ViewPaper.aspx?ID=186234

Kariman, N., Simbar, M., Ahmadi, F., \& Vedadhir, A. A. (2014a). Concerns about one's own future or securing child's future: Paradox of childbearing decision making. Health, 6, 1019-1029. http://dx.doi.org/10.4236 /health.2014.610128

Kariman, N., Simbar, M., Ahmadi, F., \& Vedadhir, A. A. (2014b). Socioeconomic and emotional predictors of decision making for timing motherhood among Iranian women in 2013. Iranian Red Crescent Medical Journal, 16.

Kariman, N., Simbar, M., Ahmadi, F., \& Vedadhir, A. A. (2015). Ambivalence, outcome of childbearing decision making among women. Journal of Shahid Beheshti School of Nursing \& Midwifery, 24(86). Retrieved from http://journals.sbmu.ac.ir/en-jnm/article/download/8461/6673

Keim, S., Klärner, A., \& Bernardi, L. (2009). Who is relevant? Exploring fertility relevant social networks. Max-Planck-Institut für demografische Forschung Working Paper, 1. Retrieved from http://www.demogr. mpg.de/

Keshavarz, G., \& Ghanbarabadi, M. B. (2012). Individual married female labor participation: An application of parametric \& non-parametric econometric analysis. Journal of Economic Research (Tahghighat-E-Eghtesadi) (JTE), 46, 151-174. Retrieved from http://en.journals.sid.ir/ViewPaper.aspx?ID= 248157

Khadivzadeh, T., Roudsari, R. L., Bahrami, M., Taghipour, A., \& Shavazi, J. A. (2013). The influence of social network on couples' intention to have the first child. Iranian Journal of Reproductive Medicine, 11, 209. PMCID: PMC3943220

Kohan, S., Simbar, M., \& Taleghani, F. (2012). Exploring women's empowerment experiences in family planning in socio-cultural context of Isfahan city: A qualitative study. Iranian Journal of Nursing Research, 7, 27-36. PMCID: PMC3696967

Kreyenfeld, M., \& Andersson, G. (2014). Socioeconomic differences in the unemployment and fertility nexus: Evidence from Denmark and Germany. Advances in Life Course Research, 21, 59-73. http://dx.doi.org/10.1016/j.alcr.2014.01.007

Long, T., \& Johnson, M. (2000). Rigour, reliability and validity in qualitative research. Clinical Effectiveness in Nursing, 4, 30-37. http://dx.doi.org/10.1054/cein.2000.0106

Mari Bhat, P. N., \& Zavier, A. J. F. (2003). Fertility decline and gender bias in Northern India. Demography, 40, 637-657. http://dx.doi.org/10.2307/1515201

Mills, M., Rindfuss, R., Mcdonald, P., \& Velde, E. (2011). Why do people postpone parenthood? Reasons and social policy incentives. Human Reproduction Update, 17, 848-860. PMCID: PMC3529638. http://dx.doi.org/10.1093/humupd/dmr026

Munro, B. H. (2005). Statistical methods for health care research. Lippincott Williams \& Wilkins. ISBN-10: 0781748402

Nejat, S., Montazeri, A., Naieni, K. H., Mohammad, K., \& Majdzadeh, S. R. (2006). The World Health Organization quality of Life (WHOQOL-BREF) questionnaire: Translation and validation study of the Iranian version. Journal of School of Public Health and Institute of Public Health Research, 4, 1-12. Retrieved from http://sjsph.tums.ac.ir/browse.php?a_code=A-10-25-187\&slc_lang=fa\&sid=1

Ní.Bhrolcháin, M., \& Beaujouan, É. (2012). Fertility postponement is largely due to rising educational enrolment. Population Studies, 66, 311-327. http://dx.doi.org/10.1080/00324728.2012.697569

Razeghi.Nasrabad, H., Shavazi, M. J. A., \& Tabatabaei, M. G. (2013). Multilevel analysis of factors effecting on firth birth timing in Iran, 1990-2000. Womens Strategic Studies, 55-94. Retrieved from http://en.journals. sid.ir/ViewPaper.aspx?ID $=297606$

Rijken, A. J., \& Knijn, T. (2009). Couples' decisions to have a first child: Comparing pathways to early and late parenthood. Demographic Research, 21, 765-802. http://dx.doi.org/10.4054/DemRes.2009.21.26

Sadeghi, J. M.-M., Tavakoli, A., \& Vahedsaeed, F. (2010). The impacts of socio-economic and emographic 
factors on fertility (Case study: Rural regions of Najaf-Abad township). Women in Development \& Politics, 8, 143-159. Retrieved from http://en.journals.sid.ir/ViewPaper.aspx?ID=178229

Samadaee-Gelehkolaee, K., Mccarthy, B., Khalilian, A., Hamzehgardeshi, Z., Peyvandi, S., Elyasi, F., \& Shahidi, M. (2014). Factors Associated With Marital Satisfaction in Infertile Couple: A Comprehensive Literature Review. Global Journal of Health Science, 8, 50086-50086.

Sedeh, M. A., ISiahpoush, A. A., \& Darvishzadeh, Z. (2012). The investigation of fertility increase and effective factors on it among the kord clan in Andimeshk. Journal of Iranian Social Development Studies, 4, 81-98. Retrieved from http://www.sid.ir/fa/VEWSSID/J_pdf/6009813901305.pdf

Snyder, C. R. (2000). The past and possible futures of hope. Journal of Social and Clinical Psychology, 19, 11-28. http://dx.doi.org/10.1521/jscp.2000.19.1.11

Söderberg, M., Christensson, K., \& Lundgren, I. (2012). A project for future life-Swedish women's thoughts on childbearing lacking experience of giving birth and parenthood. International Journal of Qualitative Studies on Health and Well-Being, 7. http://dx.doi.org/10.3402/qhw.v7i0.17318

Solchany, J. E. (2001). Promoting maternal mental health during pregnancy: Theory, practice, \& intervention, Ncast-Avenuw Pub. ISBN: 19309499529781930949959. OCLC Number: 49306192

Soleimani, A., Mahmoudi, M., \& Rahimi, A. (2005). Assessing effective factors on fertility in Mazandaran province using path analysi. Holistic Nursing and Midwifery, 15, 21-26. Retrieved from http://en. journals.sid.ir/ViewPaper.aspx?ID=51674

Taghizadeh, Z., Behmanesh, F., \& Ebadi, A. (2015). Marriage Patterns and Childbearing: Results from a Quantitative Study in North of Iran. Global journal of health science, 8, 1. http://dx.doi.org/10.5539/ gjhs.v8n3p1

Testa, M., Cavalli, L., \& Rosina, A. (2011). Couples' childbearing behaviour in Italy: Which of the partners is leading it? Vienna Yearbook of Population Research, 9, 157-178. http://dx.doi.org/10.1553/populationyear book2011s157

Testa, M., Cavalli, L., \& Rosina, A. (2012). The decision of whether to have a child: Does couple disagreement matter? Vienna Institute of Demography Working Papers. Retrieved from http://ssrn.com/abstract=2276387

Usefy, A., Ghassemi, G. R., Sarrafzadegan, N., Mallik, S., Baghaei, A., \& Rabiei, K. (2010). Psychometric properties of the Whoqol-Bref in an Iranian adult sample. Community Mental Health Journal, 46, 139-147. http://dx.doi.org/10.1007/s10597-009-9282-8

Zimet, G., Dahlem, N., Zimet, S., \& Farley, G. (1988). The multidimensional scale of perceived social support. Journal of Personality Assessment, 52, 30-41. http://dx.doi.org/10.1207/s15327752jpa5201_2

\section{Copyrights}

Copyright for this article is retained by the author(s), with first publication rights granted to the journal.

This is an open-access article distributed under the terms and conditions of the Creative Commons Attribution license (http://creativecommons.org/licenses/by/3.0/). 